\title{
Outcome of surgery versus radiotherapy after induction treatment in patients with N2 disease: systematic review and meta-analysis of randomised trials
}

\author{
P J McElnay, ${ }_{1}^{1}$ A Choong, ${ }^{2}$ E Jordan, ${ }^{3}$ F Song, ${ }^{4}$ E Lim ${ }^{5}$
}

\section{- Additional material is published online only. To view please visit the journal online (http://dx.doi.org/10.1136/ thoraxjn-2014-206292). \\ 'Department of Cardiothoracic Surgery, The Newcastle upon Tyne Hospitals NHS Foundation Trust, Newcastle, UK ${ }^{2}$ Specialty Registrar in Vascular Surgery, Imperial College Healthcare NHS Trust, London, UK ${ }^{3}$ Library Services, University Hospitals Bristol NHS Foundation Trust, Bristol, UK ${ }^{4}$ Faculty of Health, University of East Anglia, Norwich, UK ${ }^{5}$ Imperial College London and The Academic Division of Thoracic Surgery, Royal Brompton Hospital, London, UK}

\section{Correspondence to}

E Lim, Imperial College London and The Academic Division of Thoracic Surgery, Royal Brompton Hospital, Sydney Street, London SW3 6NP, UK; e.lim@rbht.nhs.uk

Received 12 September 2014 Revised 19 January 2015 Accepted 3 April 2015

Published Online First 12 May 2015
CrossMark

To cite: McElnay $P J$ Choong A, Jordan $E_{\text {, et al. }}$ Thorax 2015;70:764-768.

\section{ABSTRACT}

Objective Chemoradiotherapy is often considered the 'standard of care' for patients with N2 disease. The aim was to evaluate survival outcomes of patients with N2 disease in multimodality trials of chemotherapy, radiotherapy and surgery.

Methods Systematic review and meta-analyses (random and fixed effects) were performed. Searches of Medline and Embase (1980-2013) were conducted. Abstracts from thoracic scientific meetings were searched. Reference lists of all relevant studies were reviewed. All studies of patients with N2 disease who received induction chemotherapy or chemoradiotherapy and randomised to surgery or radiotherapy were included. No language restrictions were imposed. The main outcome was overall survival.

Results 805 publications were identified. 519 and 281 were excluded because they were not primary results from randomised trials (or did not include N2 disease) or did not compare surgery with radiotherapy, respectively. The final six trials consisted of 868 patients. In four trials, patients received induction chemotherapy and in two trials patients received induction chemoradiotherapy. The HR comparing patients randomised to surgery after chemotherapy was $1.01(95 \% \mathrm{Cl} 0.82$ to $1.23 ; \mathrm{p}=0.954)$ whereas for patients randomised to surgery after chemoradiotherapy was 0.87 ( 0.74 to $1.02 ; p=0.078)$. The overall HR of all pooled trials was 0.92 (0.81 to $1.04 ; p=0.179$ ).

Conclusions In trials where patients received surgery as part of bimodality (with chemotherapy) or trimodality (with chemoradiotherapy) treatment, overall survival was not significantly better than radiotherapy (with chemotherapy) or combination chemoradiotherapy alone.

\section{BACKGROUND}

Lung cancer is often cited as the largest cause of cancer deaths worldwide. ${ }^{1}$ Surgery is often considered to be the treatment of choice, ${ }^{2}$ but the majority of patients present with disease that is too advanced. In the UK, the current lung cancer resection rate is $21 \%,{ }^{3}$ a figure that is reflective of selection based on comorbidity and stage.

The International Association for the Study of Lung Cancer registry reported that 21\% of patients with lung cancer present with clinical N2 disease. This subgroup of patients is heterogeneous by definition and surgical treatment (alone) is often considered controversial with a published 5-year
Key messages

What is the key question?

- Should surgery be considered as part of multimodality treatment for patients with resectable lung cancer and ipsilateral mediastinal nodal disease?

What is the bottom line?

- In trials where patients received surgery as part of trimodality treatment, overall survival was associated with a HR $0.87(95 \% \mathrm{Cl} 0.74$ to 1.02) compared to chemoradiotherapy alone.

Why read on?

- In trials where patients received surgery as part of bimodality (with chemotherapy) or trimodality (with chemo-radiotherapy) treatment, overall survival was not significantly better than radiotherapy (with chemotherapy) or chemoradiotherapy alone.

survival rate in this subgroup of $25 \% .{ }^{4}$ Specifically, the lung cancer community is divided on the optimum management of patients with a resectable primary tumour, without distant metastases, but with evidence of ipsilateral mediastinal non-fixed, non-bulky lymph node (N2) disease.

The 'standard of care' is often considered to be platinum-based chemoradiotherapy despite clinical trials conducted to evaluate the role of surgery as part of multimodality treatment due to difficulties in the interpretation of the available data. The conduct and reporting of the trials have been varied with two broad designs evaluating bimodality treatment (chemotherapy and either radiother- apy or surgery) and surgery as part of trimodality treatment (chemoradiotherapy and either surgery or not). A number of trials reported marginal effects in favour of surgery that were neither statis- tically significant nor considered to be clinically important differences. ${ }^{5}$

The aim of this study is to evaluate the role of surgery in patients with N2 disease as part of bimodality and trimodality treatment in the pooled results of published clinical trials with respect to overall patient survival.

\section{METHODS}

\section{Search strategy}

We performed a systematic literature search of Medline (1980-2013) and Embase (1980-2013). 
To achieve the maximum sen- sitivity of the search strategy and identify all trials of patients with N2 disease, we used appropriate free text and thesaurus terms including among others 'Non-Small Cell Lung Carcinoma', non-small cell lung cancer and N2 (see online supplementary appendix A or the full search strategy can be obtained from EJ on request). We searched trial registers on the Internet. In order to locate unpublished work, abstracts from recent major thoracic surgery scientific meetings were searched. Reference lists of all relevant studies were reviewed and no restrictions were placed on language in any of the searches.

\section{Study selection and data abstraction}

All studies that included patients with non-small cell lung cancer and N2 disease were included. No restrictions were placed on abstracts, conference proceedings or language. Our exclusion criteria were studies that were not randomised, studies that were not confined to $\mathrm{N} 2$ disease and studies that did not compare surgery with radiotherapy after induction treatment.

Each individual trial was evaluated on the Downs and Black quality assessment tool, ${ }^{6}$ a list of 27 criteria that evaluates study reporting, external and internal validity, and has been ranked among the top six quality assessment scales suitable for use in systematic reviews. ${ }^{7}$

Two investigators (PJM, EL) assessed the papers separately according to the predetermined eligibility criteria and any discrepancies were then resolved by consensus. Percentages were converted into whole numbers for the purpose of reporting and analyses.

\section{Statistical methods}

Where published, hazard ratios and confidence intervals for overall and disease-free survival were extracted directly from the manuscript. Where confidence interval was not published, it was estimated from the P-value, and where hazard ratios were not reported, they were calculated from published summary statistics or survival plots using the method of Parmar (FS and EL). ${ }^{8}$

Random effects meta-analysis was performed by combining the results of reported or calculated individual trial HRs com- paring surgery with radiotherapy. For sensitivity analyses, we repeated the estimates obtained by fixed effects meta-analysis and also by excluding the trial of induction chemoradiotherapy.

Statistical heterogeneity of trial results were tested using the $\chi^{2}$ test of homogeneity and also expressed as $I^{2}$ : the percentage of total variability attributed to the individual trials as a measure of inconsistency between studies (a value of 50\% is regarded moderate). ${ }^{9}$ Revised (2018) statistical analyses were performed using Stata V.10.0 (StataCorp, College Station, Texas, USA). This work was performed without any funding.

\section{FINDINGS}

\section{Trial flow, characteristics and quality appraisal}

Our search strategy identified 805 publications, of which five potentially relevant trials were included, ${ }^{10-14}$ and one abstract ${ }^{15}$ that was included In total, 389 were excluded because they were not clinical trials or did not include the $\mathrm{N} 2$ disease as the sole population, and 281 trials were excluded because they did

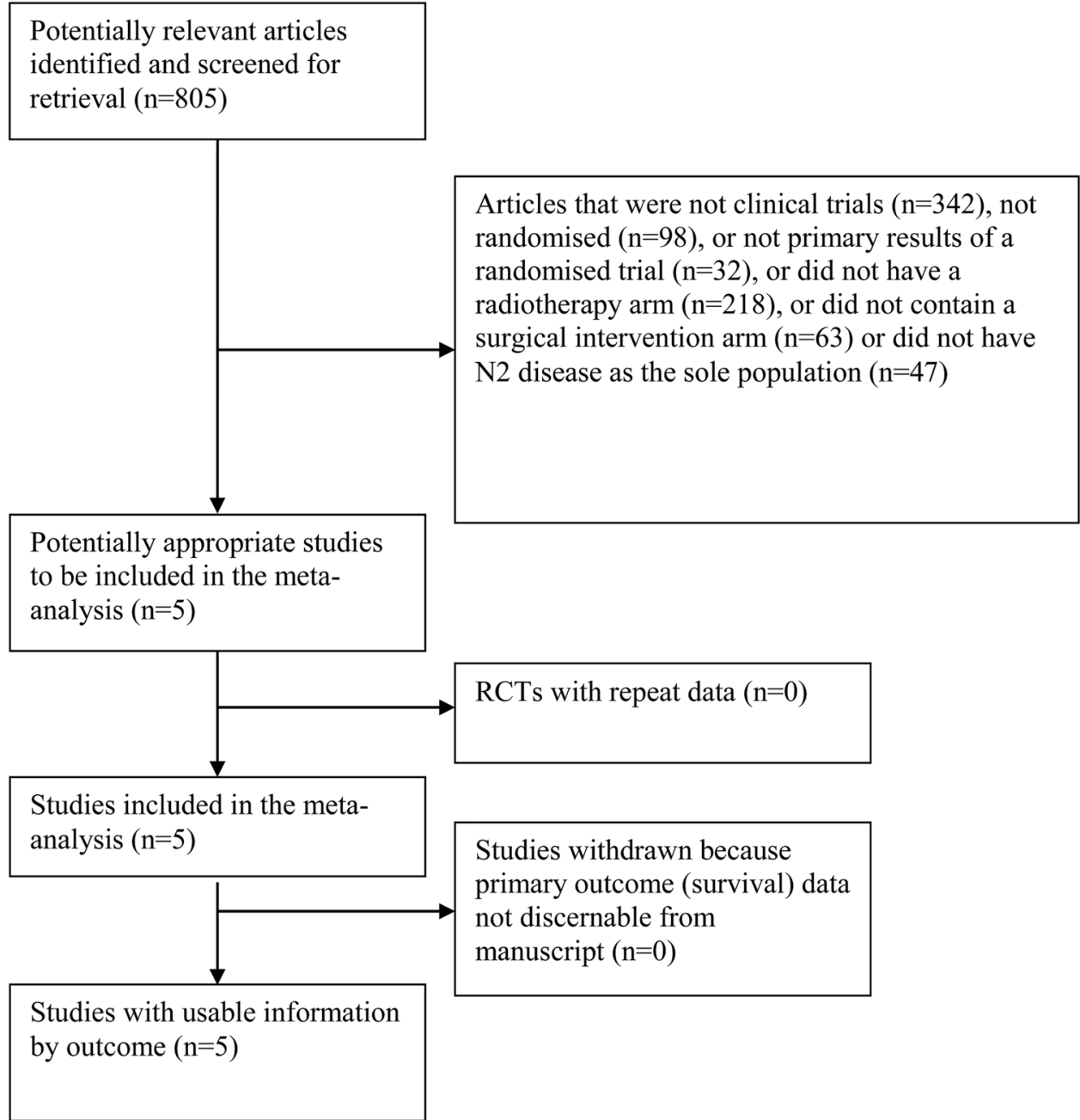

Figure 1 Quality of Reporting of Meta-analyses (QUOROM) flow diagram. RCT, randomised controlled trial. 
not compare surgery with radiother- apy as the sole treatment modalities.

The flow diagram is illustrated in figure 1 and the interventions and baseline characteristics of the included trials are summarised in table 1.

Downs and Black assessment was performed for all manuscripts that have been published, with a higher score indicating studies of higher reporting quality. It was not possible to undertake formal quality assessment of Sorensen et $a l,{ }^{15}$ as it was published in abstract format only. The overall mean (SD) score was 22(3) out of a maximum of 33.

\section{Meta-analysis}

For the primary outcome of overall survival in trials of bimodality treatment, the pooled HR for death in the surgery group was $1.01(95 \%$ CI 0.83 to $1.23 ; p=0.954)$, with no statistical evidence of heterogeneity $\left(\mathrm{I}^{2}=0 \%, \mathrm{p}=0.830\right)$, while for the primary outcome of overall survival in trials of surgery as part of trimodality treatment, the pooled HR for death in the surgery group was 0.87 (CI 0.74 to $1.02 ; \mathrm{p}=0.078$ ), again with no statistical evidence of heterogeneity $\left(\mathrm{I}^{2}=0 \%, \mathrm{p}=0.977\right)$.

Overall, the pooled HR for death in all bimodality and trimodality treatment trials (figure 2) for death in the surgical arm was $0.92(0.81$ to $1.04 ; \mathrm{p}=0.179)$, again with no statistical evidence of heterogeneity $\left(\mathrm{I}^{2}=0 \%, \mathrm{p}=0.824\right)$.

Sensitivity analysis was performed by repeating the primary analysis using fixed effects model with exactly the same result and heterogeneity estimates.

\section{DISCUSSION}

There is no area in the management of lung cancer where there is more evidence and less consensus than the subgroup of patients with resectable primary disease in the presence of non-fixed, non-bulky N2 metastases. Considerable confusion arises in the optimum pathway for staging as well as treatment selec- tion across the lung cancer guidelines in USA, ${ }^{16}$ Europe $^{17}$ and the UK. ${ }^{18}$

While there are many different recommendations for confirmatory staging or induction treatment and restaging, few appreciate that the fundamental reason for confirmatory mediastinal lymph node staging is to select patients for surgery. This in turn, is based on a prevailing view that surgery is inappropriate for patients with N2 disease. If the lung cancer community was open to surgery as a valid treatment option for patients with $\mathrm{N} 2$ disease, from the outset, no further staging (endobronchial ultrasound (EBUS) and transbronchial needle aspiration (TBNA) or mediastinoscopy and lymph node biopsies) would be recommended even if PET-CT suggests N2 positive disease.

The results of the pooled analyses of the available randomised trials to date suggest that surgery can be considered an option from the outset either as part of bimodality or trimodality management. In the bimodality trials, there was no difference in overall survival, so we would argue that both surgery and radiotherapy options are equally valid, and certainly in this setting where clinical equipoise exists (or rather when data suggest that clinical equipoise should exist), the appropriate selection of local treatment should be focused on the preference of a fully informed patient. ${ }^{19}$

In the trimodality setting, both Albain ${ }^{14}$ and Sorensen ${ }^{15}$ report a HR of 0.87 , a point estimate of $13 \%$ relative improvement in overall survival in favour of surgical multimodality management. However, the CI crosses the line of no effect and therefore it is not possible to be definitive about the effect of surgery based on these data. The results of Albain et al reported a

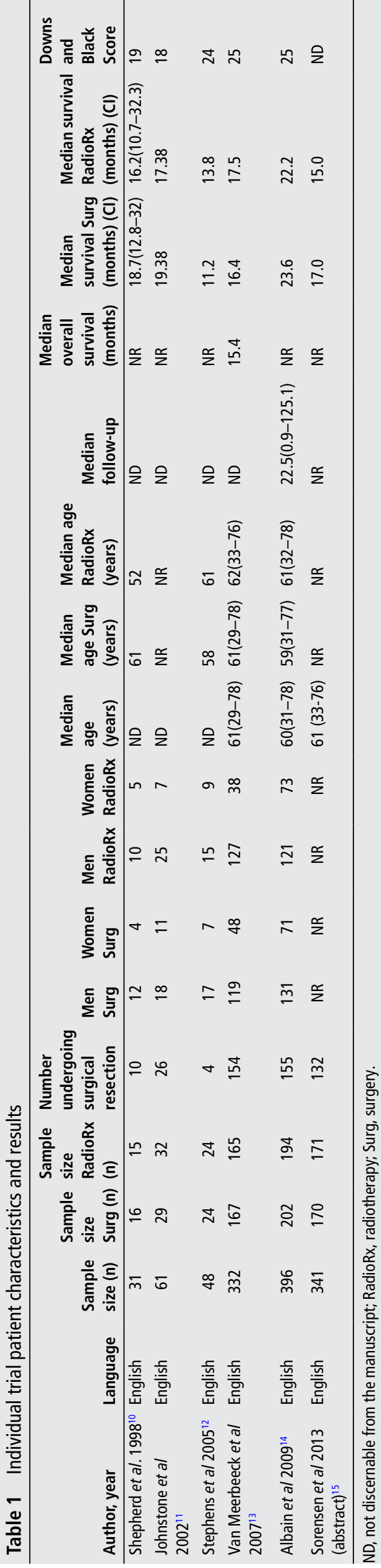




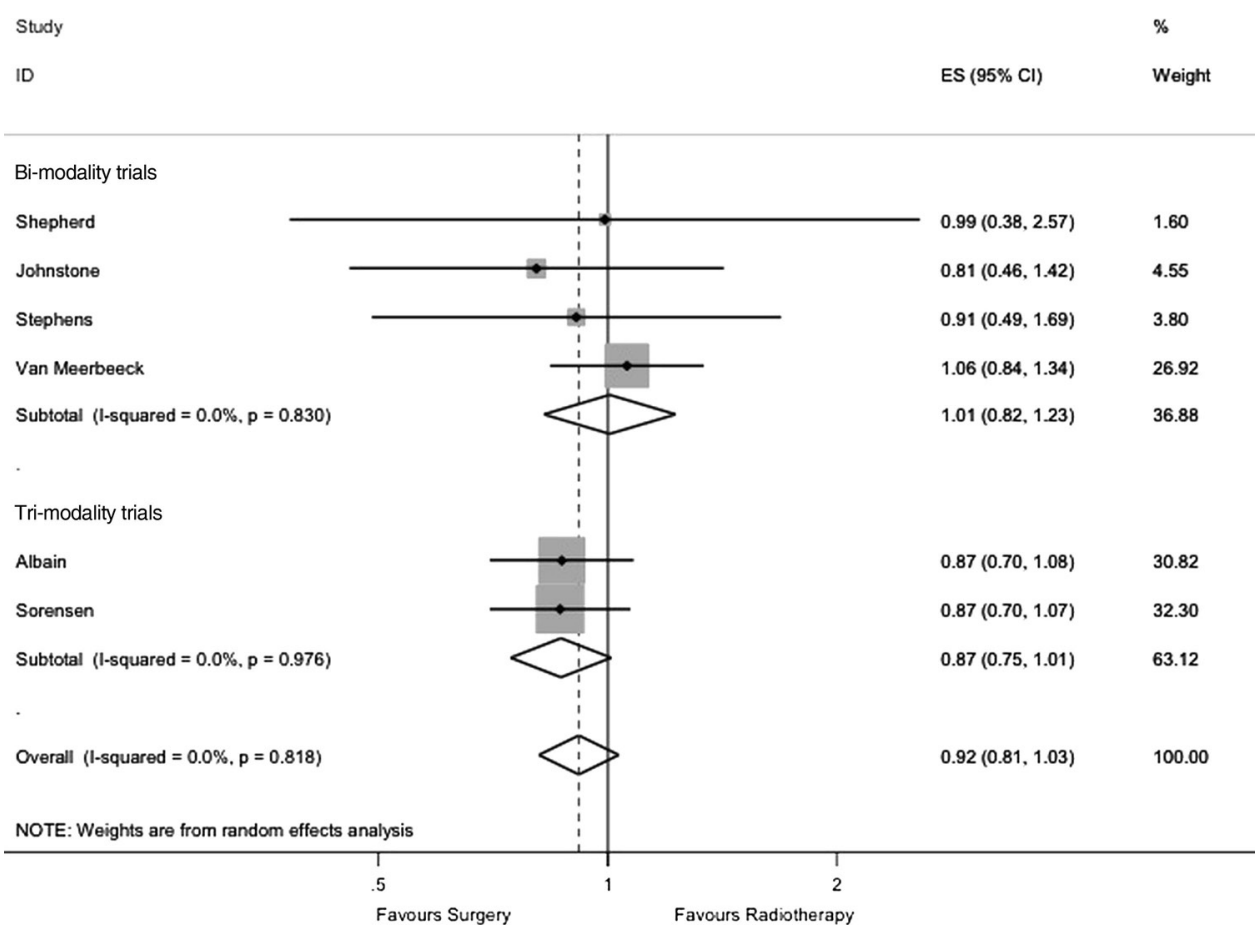

Figure 2 Forest plot of overall survival comparing postinduction surgery with radiotherapy.

significant improvement in disease-free survival in patients who were randomised to trimodality treatment. ${ }^{14}$

We included Sorensen et al, ${ }^{15}$ even though it was published only in abstract form, to avoid publication bias. Many important quality indicators for this trial remain uncertain because only the abstract is available. We have contacted the authors of the Sorensen trial but have no additional unpublished information at the time of writing.

This is a cohort of patients and, as a result, a group of studies that can be difficult to compare. Indeed, there have also been changes in the investigation of these patients over the past several years including the introduction of Positron Emission Tomography scanning and Endobronchial Ultrasound in the post induction setting. Further, all the pooled trials to date did not distinguish between single node/zone and multi-node/zone involvement and, therefore, we were not able to comment on this distinction. In our opinion, therefore, there should be no clinical distinction (as the trials included patients with multi- node/ station involvement). In the Albain trial, $22 \%$ of patients enrolled had two or more stations involved..$^{14}$ Finally, trials did not always comment on the proportion of lobectomies and pneumonectomies performed in the surgical arm and hence we were not able to undertake such a subanalysis.

Although chemoradiotherapy has long been considered to be the standard of care in patients with clinical N2 disease, ${ }^{2}$ the result of our systematic review and meta-analyses suggests no important differences in overall survival in patients randomised to surgery as part of bimodality treatment, and improved survival (which does not reach statistical significance) in patients randomised to surgery as part of trimodality treatment. Therefore, in patients with a resectable primary tumour and ipsilateral non-bulky mediastinal lymph node disease, should clinicians and patients decide on surgical bimodality management, surgery is undertaken as an alternative to radiotherapy for local control of the cancer without expectation of difference in survival, whereas surgical trimodality treatment would be offered with the expectation of improving survival (acknowledging uncertainty as conventional levels of statistical significance were not achieved). Ultimately the management of choice should be patient-led and tailored to individual patients' physiological status.

Surgery can be considered as a multimodality treatment option for patients with resectable lung cancer and non-bulkyipsilateral mediastinal lymph node disease, as survival outcomes were similar to medical treatment in both bimodality and trimodality settings.

\section{Twitter Follow Philip McElnay at @phil_mce and Eric Lim at @ekslim}

Contributors PJM: Acquisition, analysis and interpretation of the data, drafting and revising the manuscript, final approval of the submitted version and agreement to be accountable for all aspects of the work. AC: Acquisition, analysis and interpretation of the data, drafting and revising the manuscript, final approval of the submitted version and agreement to be accountable for all aspects of the work. EJ: Acquisition, analysis and interpretation of the data, drafting and revising the manuscript, final approval of the submitted version and agreement to be accountable for all aspects of the work. FS: Design of the work, data analysis, drafting and revising the manuscript, final approval of the submitted version and agreement to be accountable for all aspects of the work. EL: Conception and design of the work, analysis and interpretation of the data, drafting and revising the manuscript, final approval of the submitted version and agreement to be accountable for all aspects of the work.

Competing interests All authors have completed the ICMJE uniform disclosure form at http://www.icmje.org/coi_disclosure.pdf and declare no support from any organisation for the submitted work. PM, AC, EJ and FS have no financial relationships with any organisation that might have an interest in the submitted work in the previous 3 years and no other relationships or activities that could appear to have influenced the submitted work. EL reports personal fees from Abbott Molecular, personal fees from Glaxo Smith Kline, personal fees from Pfizer, personal fees from Norvatis, Covidien, Roche, Lily Oncology, Boehringer Ingelheim, Medela and grants and personal fees from ScreenCell, outside the submitted work; and he is the founder of Informative Genomics, a blood based molecular diagnostic company based in London.

Provenance and peer review Not commissioned; externally peer reviewed.

Data sharing statement All authors had full access to all of the data in the study and can take responsibility for the integrity of the data and the accuracy of the data analysis. EL (corresponding author) affirms that the manuscript is an honest, accurate and transparent account of the study being reported and that no important aspects of the study have been omitted.

\section{REFERENCES}

1 Ferlay J, Shin H, Bray F, et al. Estimates of worldwide burden of cancer in 2008: GLOBOCAN 2008. Int J Cancer 2010;127:2893-917. 
2 D'Addario G, Felip E. On behalf of the ESMO Guidelines Working Group. Non-smallcell lung cancer: ESMO Clinical Recommendations for diagnosis, treatment and follow-up. Ann Oncol 2010;21(S4):iv68-70.

3 Health and Social Care Information Centre. National Lung Cancer Audit Report. 2013. http://www.hqip.org.uk/assets/NCAPOP-Library/NCAPOP-2013-14/ NLCA2013INTERACTIVE-PDF26-11-13.pdf (accessed on: 5 May 2014).

4 Rusch VW, Crowley J, Giroux DJ, et al. The IASLC Lung Cancer Staging Project: proposals for the revision of the $\mathrm{N}$ descriptors in the forthcoming seventh edition of the TNM classification for lung cancer. J Thorac Oncol 2007;2:603-12.

5 Lim E, Harris G, Patel A, et al. Preoperative versus postoperative chemotherapy in patients with resectable non-small cell lung cancer: systematic review and Indirec Comparison Meta-Analysis of Randomized Trials. J Thorac Oncol 2009;4:1380-8.

6 Downs S, Black N. The feasibility of creating a checklist for the assessment of the methodological quality both of randomised and non-randomised studies of health care interventions. J Epidemiol Community Health 1998;52:377-84.

7 Deeks JJ, Dinnes J, D'Amico R, et al. Evaluating non-randomised intervention studies. Health Technol Assess 2003;7:1-173.

8 Parmar MK, Torri V, Stewart L. Extracting summary statistics to perform meta-analyses of the published literature for survival endpoints. Stat Med 1998;17:2815-34.

9 Higgins JP, Thompson SG, Deeks JJ, et al. Measuring inconsistency in meta-analyses. BMJ 2003;327:557-60.

10 Shepherd FA, Johnston MR, Payne D, et al. Randomized study of chemotherapy and surgery versus radiotherapy for stage IIIA non-small-cell lung cancer: a National Cancer Institute of Canada Clinical Trials Group Study. Br J Cancer 1998;78:683-5.

11 Johnstone DW, Byhardt RW, Ettinger D, et al. Phase III study comparing chemotherapy and radiotherapy with preoperative chemotherapy and surgical resection in patients with non-small-cell lung cancer with spread to mediastinal lymph nodes (N2); final report of RTOG 89-01. Radiation Therapy Oncology Group. Int J Radiat Oncol Biol Phys 2002;54:365-9.

12 Stephens RJ, Girling DJ, Hopwood P, et al. A randomised controlled trial of preoperative chemotherapy followed, if feasible, by resection versus radiotherapy in patients with inoperable stage T3, N1, M0 or T1-3, N2, M0 non-small cell lung cancer. Lung Cancer 2005;49:395-400.

13 van Meerbeeck JP, Kramer GW, Van Schil PE, et al. Randomized controlled trial of resection versus radiotherapy after induction chemotherapy in stage IIIA-N2 nonsmall-cell lung cancer. J Natl Cancer Inst 2007;99:442-50.

14 Albain KS, Swann RS, Rusch VW, et al. Radiotherapy plus chemotherapy with or without surgical resection for stage III non-small-cell lung cancer: a phase III randomised controlled trial. Lancet 2009;374:379-86.

15 Sorensen JB, Ravn J, Pilegaard HK, et al. Surgery for NSCLC stages T1-3N2MO having preoperative pathologically verified $\mathrm{N} 2$ involvement: A prospective randomized multinational phase III trial by the Nordic Thoracic Oncology Group. J Clin Oncol 2013;31(15 suppl):7504

16 Schwartz AM, Rezaei MK. Diagnostic surgical pathology in lung cancer: Diagnosis and management of lung cancer, 3rd edition: American college of chest physicians evidence-based clinical practice guidelines. Chest 2013;143(5 Suppl):e251S-62S.

17 Vansteenkiste J, De Ruysscher D, Eberhardt W, et al. on behalf of the ESMO Guidelines Working Group. Ann Oncol 2013;24(Suppl 6):vi89-98.

18 National Institute for Health and Clinical Excellence. Clinical Guideline 21: The diagnosis and treatment of lung cancer. 2011. http://www.nice.org.uk/nicemedia/ live/13465/54202/54202.pdf (accessed on 5 May 2014).

19 Lim E. Patients' perspective in the surgical decision-making process. Thorac Surg Clin 2012;22:539-43. 


\section{Correction: Outcome of surgery versus radiotherapy after induction treatment in patients with N2 disease: systematic review and meta-analysis of randomised trials}

McElnay PJ, Choong A, Jordan E, et al. Outcome of surgery versus radiotherapy after induction treatment in patients with $\mathrm{N} 2$ disease: systematic review and meta-analysis of randomised trials. Thorax 2015;70:764-8. doi:10.1136/thoraxjnl-2014-206292

Significant changes have been made to the text of this article since it first published online and in print. The correct version is available online here: http://dx.doi.org/10.1136/ thoraxjnl-2014-206292

(C) Author(s) (or their employer(s)) 2019. No commercial re-use. See rights and permissions. Published by BMJ.

Thorax 2019;74:824. doi:10.1136/thoraxjnl-2014-206292corr1

D) Check for updates 